\title{
Comunidades quilombolas e educação fundamental: o ensino das brincadeiras de folia (curraleira) nas aulas de educação física escolar
}

\author{
Reigler Siqueira Pedroza* \\ Marcelo Carneiro dos Santos** \\ Diogo Geraldo da Silva Guedes ${ }^{* * *}$ \\ Rívia Maria Alves dos Santos ${ }^{* * * *}$
}

\section{Resumo}

Esta pesquisa teve por objetivo desenvolver uma proposta pedagógica para o ensino dos saberes da cultura afro-brasileira, em especial das comunidades quilombolas de Goiás, nas aulas de educação física escolar. A metodologia utilizada foi a pesquisa-ação, que possibilitou a construção, juntamente com a escola, de um processo de ensino-aprendizagem que articulasse os saberes da cultura popular de uma comunidade quilombola de Goiás a uma prática pedagógica para a primeira fase do ensino fundamental. Então, a partir da classificação e sistematização dessa prática social, mediada por uma teoria pedagógica crítica, construímos uma metodologia que problematizou as brincadeiras de folia (curraleira) na escola, considerando sua complexidade como linguagem corporal através das rimas/cantos, musicalidade, por meio dos instrumentos de percussão, gestualidade técnica para realização da dança e fluidez como expressão artística de uma totalidade significativa. Em síntese, foi possível elaborar uma práxis pedagógica que tematizasse a cultura afro-brasileira e suas interfaces com a educação física escolar, da qual destacamos a aprendizagem dos alunos sobre a folia como conhecimento histórico do homem do campo.

Palavras-chave: comunidades quilombolas, folia, educação física escolar, dança.

Quilombo communities and fundamental education: the teaching of folia (curraleira) jobs in school physical education classes

\begin{abstract}
This research has as general objective to develop a pedagogical proposal for the teaching of the knowledge of the Afro-Brazilian culture, especially of the quilombola communities of Goiás, in the school physical education classes. The methodology used was the action research that enabled the construction, together with the school, of a process of teaching learning that articulated the knowledge of popular culture of a Quilombola community of Goiás in a pedagogical practice for the first phase of elementary school. We produced with this work a classification and systematization of this social practice that, based on a critical pedagogical theory, made possible the creation of a methodology to problematize folia jokes (curraleira). In summary, it was possible to construct a pedagogical praxis that thematized Afro-Brazilian culture and its interfaces with school physical education, from which we highlight students' learning about folia as a historical knowledge of rural man. From which he sought to contemplate his complexity as body language through rhymes/songs, musicality through percussion instruments, technical gestures for dance performance and fluidity as an expression of a significant totality that composes the creative process of the social practice of the human race.
\end{abstract}

Keywords: quilombo communities, folia, physical education, dance.

\footnotetext{
* Professor do curso de licenciatura em Educação Física da ESEFFEGO/UEG e doutorando do programa strictu sensu da FEF/UnB.

*** Mestrando do programa strictu sensu da FEF/UnB.

*** Acadêmico do curso de licenciatura em Educação Física da ESEFFEGO/UEG.

***** Acadêmica do curso de licenciatura em Educação Física da ESEFFEGO/UEG.
} 


\section{Introdução}

Este trabalho analisa uma prática pedagógica desenvolvida em uma escola da Rede Municipal de Ensino (RME) de Goiânia/GO, por intermédio do Pibid (Programa Institucional de Bolsas de Iniciação à Docência), a partir do subprojeto de Educação Física da Universidade Estadual de Goiás (UEG), campus Eseffego (Escola Superior de Educação Física e Fisioterapia de Goiás).

Este programa nacional de formação de professores almeja que os acadêmicos de licenciatura qualifiquem sua formação docente com uma aproximação, já no início do curso, da organização do trabalho pedagógico da escola. No caso específico deste subprojeto, definimos como prioridade o desenvolvimento de propostas pedagógicas que problematizassem os saberes históricos advindos da cultura afro-brasileira e indígena nas aulas de educação física escolar. Isso porque, apesar das legislações que obrigam o trato desses conhecimentos nos currículos escolares, estes ainda são negligenciados nas práticas pedagógicas dos professores, em sua grande maioria, pela falta de saberes sistêmicos que subsidiem essas práticas pedagógicas.

Diante desse cenário e a partir da Lei n. ${ }^{\circ} 10.639$, de 9 de janeiro de 2003, Art. $1^{\text {o }}$ (BRASIL, 2003), que obriga o ensino de conteúdos referentes à História e à Cultura Afro-Brasileira na escola, debruçamo-nos no desafio de sistematização dessa proposta pedagógica. Se considerarmos os saberes advindos da cultura afro-brasileira, em especial de comunidades quilombolas, notamos uma invisibilidade desses grupos sociais no currículo escolar e a desconsideração desses conhecimentos nos projetos educacionais. Assim, tendo por base esse cenário, propusemo-nos a construir uma proposta pedagógica que tematizasse o ensino das brincadeiras de folia a partir da especificidade regional das comunidades quilombolas de Goiás. Desse modo, buscamos superar não somente a restrição histórica da educação física escolar ao esporte como saber curricular prioritário, como também da dança, que, ao ser problematizada, fica circunscrita aos conhecimentos eurocêntricos, marginalizando os advindos da cultura afro-brasileira. Esta proposta pedagógica, tomando por referência a folia, permitiu trabalhar os seguintes saberes específicos da dança: a espacialidade, a sinestesia e a linguagem corporal. 
A seleção desse conteúdo adveio de um estado da arte realizado dentro do Pibid para refletir criticamente sobre a educação física, a dança e suas interfaces com a cultura afro-brasileira. A fundamentação teórica para a sistematização desta intervenção pedagógica foi a dissertação de mestrado de Pedroza (2013), que elaborou uma etnografia da Folia de São Sebastião da Comunidade Quilombola Magalhães, localizada na zona rural do município de Nova Roma-GO. Esse estudo permitiu classificar e analisar a complexidade do ritual da folia nas suas diversas performances (agasalho, canto para o dono da casa, bendito de mesa, brincadeiras - curraleira, catido, corrido, sussa, catira, batucada etc - e despedida), no que tange à estrutura do "giro". Isso porque a totalidade do processo ritualístico é composto por uma tríade: a saída, o giro e a entrega da folia. Assim, delineamos o ensino da cultura afro-brasileira na escola, dando destaque para as comunidades quilombolas de Goiás, especialmente a curraleira, uma das brincadeiras de folia.

Portanto, o objetivo geral foi elaborar uma proposta pedagógica para as aulas de educação física escolar que problematizasse, nas aulas de dança, os saberes da cultura afro-brasileira, tematizando as brincadeiras de folia (curraleira) no ensino fundamental. Já os específicos foram: a) identificar as curraleiras como saber constitutivo das folias e festejos regionais do estado de Goiás; b) aprender os aspectos fundamentais desta prática social contextualizados nos saberes universais da dança: o espaço, o tempo (ritmo) e o movimento; c) ensinar os aspectos sócio-históricos que constituem a folia como expressão da cultura camponesa no estado de Goiás (vestimentas, ritos, costumes, entre outros).

\section{Fundamentação Teórica}

\subsection{Comunidades quilombolas de Goiás, foliae educação física escolar}

De acordo com Almeida (2002), é necessário superar a concepção de que os quilombos eram grupos estáticos, sem resistência e negadores do sentido de mobilidade, inter-relações e diversidade no seu interior. Pelo contrário, eles possuíam diversidade étnica e social caracterizada pelo quadro de exclusão e conflito social com a colônia. O quilombo tornou-se emblemático no processo de resistência ao regime escravista, que se sustentava na força física e no poder simbólico. 
Quanto ao termo quilombo, a partir da Constituição de 1988, este adquire uma interpretação atualizada, ao ser contemplado no artigo 68 do Ato das Disposições Constitucionais Transitórias (ADCT), porque se reconheceu o direito territorial às comunidades remanescentes de quilombo que ainda ocupavam suas terras, cabendo às políticas públicas o dever de garantir o reconhecimento e titulação dessas terras. Essa nova configuração política, como nos aponta O'Dwyer (2002), confere ao termo quilombo a conotação de direitos territoriais, reconfigurando o conceito de quilombo e seu uso social na contemporaneidade, pois se desloca de uma dimensão histórica para uma possibilidade de reivindicação de direitos sociais.

Na região Centro-Oeste, especificamente em Goiás, de acordo com a Fundação Cultural Palmares (2012), temos atualmente 22 comunidades quilombolas reconhecidas dentro do estado. Sabemos que esse número está aquém da realidade, porque, se tomarmos como exemplo o estado vizinho de Minas Gerais, de acordo com a mesma fonte de consulta, este já possui 158 reconhecidas. A partir desse dado, se comparado com a realidade de Goiás, é possível termos uma dimensão do tamanho da invisibilidade social que vêm enfrentando essas comunidades tradicionais em nossa localidade. Dentre essas 22 comunidades quilombolas que tiveram seu reconhecimento pela Fundação Palmares, a única que conseguiu conquistas significativas na disputa política pela posse da terra foi a comunidade quilombola Kalunga.

O surgimento dos quilombos em Goiás, de acordo com Karasch (1996), ocorreu por volta do século XVII com a fuga de escravos indígenas dos centros de extração do ouro localizados no norte do estado. Silva (1998) relata que, nesse período, vieram para cá africanos fugidos do Maranhão, Bahia e Pernambuco, percorrendo a rota do sertão com destino às regiões norte e nordeste do estado. Já Almeida (2007) afirma que esses quilombos se autossustentavam por meio da mineração de ouro e do cultivo de alimentos. Sem dúvida, a mineração é uma diferença que marca as comunidades surgidas em Goiás, uma vez que garimpavam em montanhas remotas da região e trocavam esse ouro por mercadorias nos municípios próximos para utilizá-las nos quilombos, tais como armas, munição, cachaça e tecidos. Esses sujeitos eram nomeados, no final do século XIX e até segunda metade do século XX, de "negros do leste goiano". Essa nomenclatura perdurou até a divisão do norte de Goiás em 1989 para 
a criação de um novo estado, nomeado de Tocantins. A partir desse momento, os "negros do leste goiano" passam a pertencer ao nordeste de Goiás.

Os estudos antropológicos sobre as comunidades quilombolas, sejam em Goiás ou nos estados circunvizinhos, têm direcionado seu olhar para as dimensões culturais, identitárias, fundiárias e políticas, como demonstra os trabalhos de Almeida (2002), O'Dwyer (2002), Alvarez (2006), Almeida (2007) e Ratts (2003). Nesse sentido, vemos uma ampliação das pesquisas e das possibilidades de análise dessa realidade social. Sob esta nova perspectiva, as etnografias realizadas na contemporaneidade têm auxiliado no reconhecimento dessas comunidades quilombolas como populações negras ocupantes de territórios tradicionais, rurais e urbanos (ALMEIDA, 2002), superando as visões que as homogeneizavam, como fizeram alguns estudos de caráter histórico.

A folia ou dança da folia, como também é conhecida, de acordo com Brandão (1983), surge no período medieval nos salões nobres em conjunto com as igrejas medievais. Foi trazida para o Brasil pelos missionários jesuítas na forma de versos e danças que abordavam os dramas de piedade cristã, fazia parte do repertório de teatro catequético e, por esse motivo, era imposta aos indígenas. Dos aldeamentos indígenas se espalhou por confrarias e irmandades religiosas de todo o país, em especial de grupos negros localizados nas regiões Norte, Nordeste e Centro-Oeste do país, além de Minas Gerais. No período de romanização do catolicismo brasileiro, os ritos considerados festivos aos poucos vão sendo expulsos dos templos e ganham as ruas, as praças, as periferias das cidades e as estradas e terreiros do meio rural. Essa apropriação popular de cultos e crenças trazidas pela Igreja Católica leva a uma prática religiosa autônoma, diminuindo o controle da hierarquia eclesiástica.

Sendo assim, a folia

(...) sobrevive em redutos de cultura camponesa, multiplica-se entre incontáveis equipes, grupos e confrarias de foliões. Unidades populares de trabalho religioso, equipes estáveis de especialistas camponeses que realizam uma fração do trabalho popular de fazer com que circule na comunidade e entre comunidades rurais (depois urbanas, quando o lavrador começa a migrar para a beira das cidades) o saber coletivo de crenças de fé, ritos de piedade e regras de vida. (BRANDÃO, 1983, p. 16; grifos do autor)

Por conta disso, as folias são organizadas hierarquicamente de acordo com o saber/poder que cada um possui a respeito daquela tradição cultural. A partir dessa 
perspectiva, a análise das situações rituais da folia permite interpretar aspectos da organização social do "homem camponês".

Em síntese, entendemos que o ritual de folia, segundo Pessoa et al (2007), ao fazerem referência a folcloristas e antropólogos, como Câmara Cascudo e Carlos Rodrigues Brandão, possui três características fundamentais. A primeira delas classifica-a como pertencente ao catolicismo popular; a segunda, e relacionada com a primeira, a reconhece como sendo de origem camponesa; e, por último, a descreve como um peditório de cortejo que é feito em nome de um padroeiro. A partir dessa premissa, construímos uma proposta de ensino das brincadeiras de folia para a escola, tomando como ponto de partida a educação física como componente curricular obrigatório.

Cabe destacar ainda que entendemos a escola como um espaço privilegiado para a transmissão do saber elaborado e sistematizado de maior relevância histórica para a formação do gênero humano, como nos destaca Saviani (1997). Portanto, a educação física é uma prática social, manifestada na forma de linguagem corporal, que, ao ser classificada e sistematizada para a educação formal, tem como objeto de estudo a cultura corporal como mediadora de sua práxis pedagógica (COLETIVO DE AUTORES, 1992). Sendo assim, debruçamo-nos neste trabalho objetivando a elaboração de uma proposta pedagógica que problematize a cultura afro-brasileira.

\section{Metodologia}

Esta proposta pedagógica valeu-se, no campo da pesquisa, como fundamentação teórico-metodológica mediadora com a realidade concreta, da pesquisa-ação, na qual buscamos materializar a relação dialética entre planejamento, ação, reflexão e uma nova ação (transformadora da realidade) para a práxis pedagógica da escola. O trabalho envolveu os seguintes momentos: a) pesquisa e estudos dos referenciais teóricos produzidos no campo da cultura afro-brasileira, educação e educação física escolar; b) planejamento e intervenção pedagógica em conjunto com o professor supervisor da escola que contribuiu para a organização do trabalho pedagógico na instituição. Essa intervenção permitiu uma prática pedagógica inovadora que foi construída na relação entre educação básica e universidade (DEMO, 1997), realizando as seguintes atividades 
como princípio da ação educativa: a) produção de materiais curriculares relacionados aos conteúdos da cultura corporal, elementos constitutivos da educação física escolar; b) elaboração de sequências pedagógicas a partir de uma análise da realidade dos alunos e de suas possibilidades de aprendizagem; c) construção e implementação de instrumentos avaliativos formais do processo de ensino-aprendizagem dos alunos; d) consolidação de estudos investigativos acerca da realidade da educação física como componente curricular obrigatório da rede pública de ensino, e produção de formas inovadoras de pedagogização das manifestações da cultura corporal advindas da cultura afro-brasileira.

\section{Análise dos dados (relato da proposta pedagógica)}

Como já explicitado, nosso recorte está circunscrito ao que denominamos de "brincadeiras de folia", em especial a curraleira. A proposta pedagógica teve como preocupação construir uma intervenção pedagógica que problematizasse os saberes da cultura afro-brasileira, regionalizada e delimitada ao estado de Goiás. Então, a partir dos apontamentos feitos por Pedroza (2013), realizamos um trabalho teleológico de classificar, sistematizar e pedagogizar as brincadeiras de folia com a intencionalidade de ensiná-las no Ciclo I (primeira fase do ensino fundamental).

Com a delimitação dos saberes curriculares, percebemos a dificuldade de planejar uma prática pedagógica na escola com crianças de 7- 8 anos de idade, a partir da especificidade do conhecimento selecionado, seja pela ausência de procedimentos didáticos, seja pelas limitações teórico-metodológicas que enfrentaríamos com a realidade. E isso levou à decisão de planejar uma proposta de intervenção delimitada à especificidade da dança como conteúdo das aulas de educação física escolar. Segundo Strazzacappa (2003), a dança permite aos seus participantes adentrar num universo imaginativo e criativo mediado por sua realidade concreta. É importante destacar a coparticipação do professor de educação física da escola na mediação desse processo pedagógico, no qual sua experiência docente e contribuições didáticas foram fundamentais para a realização do trabalho.

Dessa forma, as aulas foram estruturadas em 12 dias letivos, sendo estas geminadas em duas aulas e com duração de duas horas cada, tendo assim um total de 24 aulas para a intervenção pedagógica. Por conta de um movimento de greve na RME, 
que durou cerca de três meses, essas aulas não puderam ser ministradas na sua totalidade, o que obrigou a uma reestruturação das mesmas. No retorno, as aulas foram planejadas em oito intervenções (Conforme a tabela 1), mantendo-se a lógica das aulas geminadas, totalizando 16 aulas para o trimestre. As intervenções foram realizadas às quartas-feiras, das $15 \mathrm{~h} 20$ às $17 \mathrm{~h} 20$, por um grupo composto por três bolsistas, que se alternavam nas regências com o acompanhamento do professor supervisor da instituição. Os alunos pertenciam à Turma B2 do Ciclo 1, com idade entre sete e oito anos. Diante dessa realidade concreta, realizamos o seguinte fluxo programático:

Tabela 1 - Planejamento das intervenções

\begin{tabular}{|c|c|c|}
\hline Aula/ Dia & Conteúdo & Objetivo \\
\hline $\begin{array}{l}06 / 08 \\
1 \text { e } 2\end{array}$ & Histórico da folia & $\begin{array}{l}\text { Contextualizar a folia, bem como a realização da } \\
\text { festa (tempo de festa), valores e costumes dessa } \\
\text { tradição cultural e suas expressões performativas. }\end{array}$ \\
\hline $\begin{array}{l}13 / 08 \\
3 \text { e } 4\end{array}$ & $\begin{array}{l}\text { Dança da curraleira, } \\
\text { ritmos e } \\
\text { instrumentos }\end{array}$ & $\begin{array}{l}\text { Conceituar e classificar a folia, os papéis sociais } \\
\text { dos foliões, as vestimentas e os instrumentos } \\
\text { utilizados. }\end{array}$ \\
\hline $\begin{array}{l}20 / 08 \\
5 \text { e } 6\end{array}$ & $\begin{array}{l}\text { Dança da curraleira } \\
\text { (ritmo e primeiros } \\
\text { passos) }\end{array}$ & $\begin{array}{l}\text { Aprenderas técnicas de dança da curraleira, } \\
\text { considerando seu ritmo e espacialidade, dando } \\
\text { destaque às trocas e giros entre os foliões. }\end{array}$ \\
\hline $\begin{array}{l}27 / 08 \\
7 \text { e } 8\end{array}$ & & \\
\hline $\begin{array}{l}03 / 09 \\
9 \text { e } 10\end{array}$ & $\begin{array}{l}\text { Dança da curraleira } \\
\text { (cantos e } \\
\text { musicalidade - } \\
\text { instrumentos) }\end{array}$ & $\begin{array}{l}\text { Ensinar as rimas/cantos de curraleira e } \\
\text { manipulação dos instrumentos. }\end{array}$ \\
\hline $\begin{array}{c}10 / 09 \\
11 \text { e } 12\end{array}$ & & \\
\hline
\end{tabular}




\begin{tabular}{|c|l|l|}
\hline $17 / 09$ & $\begin{array}{l}\text { Desenho avaliativo } \\
\text { e ensaio }\end{array}$ & $\begin{array}{l}\text { Identificaros saberes culturais apreendidos pelos } \\
\text { alunos no processo de ensino-aprendizagem da } \\
\text { folia. }\end{array}$ \\
\hline $24 / 09$ & $\begin{array}{l}\text { Ensaio e } \\
\text { apresentação }\end{array}$ & $\begin{array}{l}\text { Realização de uma coreografia performática de } \\
\text { folia (curraleira) a ser publicizada em atividade } \\
\text { coletiva na escola. }\end{array}$ \\
\hline
\end{tabular}

Fonte: Elaborado pelos autores.

A partir desse cenário que compõe a totalidade do processo de ensinoaprendizagem, explicitamos agora uma descrição/análise dos aspectos teóricometodológicos que conduziram a práxis pedagógica. A justificativa de se trabalhar com o recorte da curraleira, já anunciado na fundamentação teórica, aglutinou-se com o fato de o conteúdo das aulas de educação física naquele trimestre ser dança. Mesmo as expressões performáticas da folia possuindo aspectos da religiosidade brasileira, defendemos a laicidade da escola como instituição de um Estado republicano. Já no caso específico das brincadeiras, há uma multiplicidade de manifestações que dialogam com o cotidiano, com as transformações sociais e as contradições nas formas de sociabilidade humana.

De acordo com Lima (2013), a curraleira é uma dança que consiste em palmas e sapateados, semelhantes à catira, sendo dançada somente por homens, pelos próprios músicos e foliões. O processo da curraleira em si se dá por meio de uma sequência de movimentos que é acompanhada por alguns instrumentos, como caixa, pandeiro e viola. Os movimentos que são executados dentro da dança seguem a esta ordem: inicia-se com duas fileiras de oito pessoas cada, onde haverá trocas de foliões que estão em lados opostos constantemente e com giros sincronizados entre os foliões. As figuras produzidas abaixo ilustram didaticamente a movimentação dos foliões, orientando assim todo o processo de ensino-aprendizagem. 
132 Polyphonía, v. 29/1, jan./jun. 2018

Figura1 - Diagrama didático de ensino da Curraleira (parte 01)

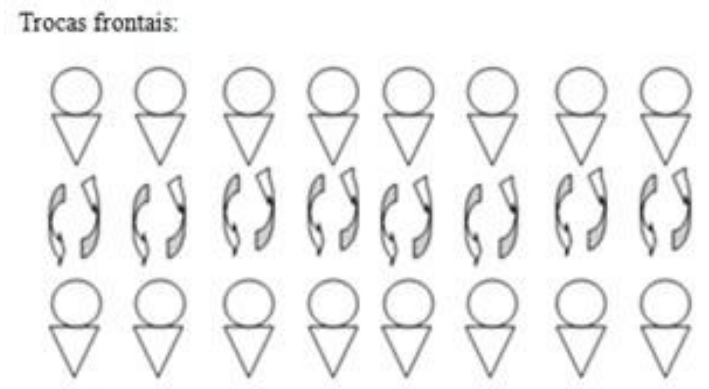

Figura 2 -Diagrama didático de ensino da Curraleira (parte 02)

Trocas laterais;

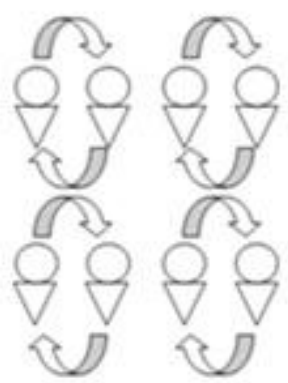

Figura3 - Diagrama didático de ensino da Curraleira (parte 03)

Giro em quartetos;

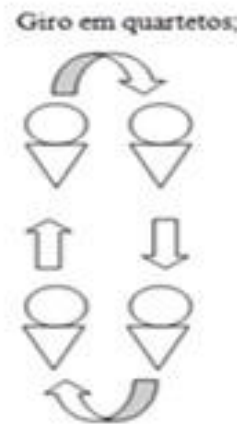


Figura 4 - Diagrama didático de ensino da Curraleira (parte 04)

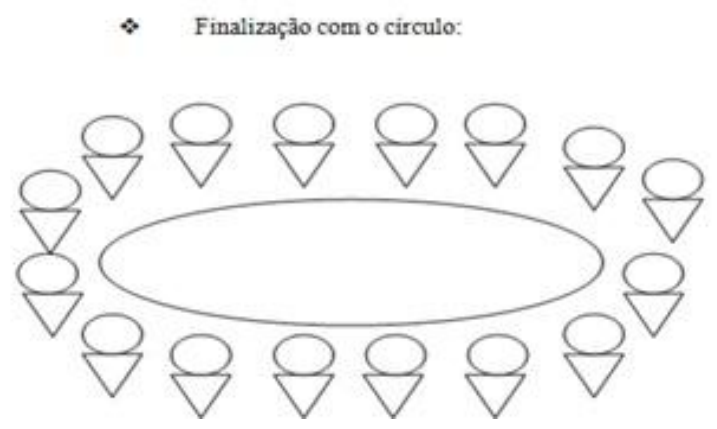

Fonte: Elaborados pelos autores.

\subsection{O processo de ensino-aprendizagem da curraleira}

No processo de pedagogização da curraleira nas aulas de educação física, utilizamos marcações no chão feitas com giz de cera para orientar os alunos e setas indicadoras da estrutura de movimentação dos foliões para a aprendizagem da dança. Então, as aulas foram iniciadas com demonstrações em vídeo de danças populares pelo mundo, como valsa, dança do ventre, hip hop. Isso teve o intuito de classificar os saberes da dança como conhecimento sistêmico da historicidade humana, localizando a folia como uma expressão da cultura popular brasileira que se singulariza no contexto das comunidades quilombolas. Os alunos demonstraram conhecer não a curraleira em si, mas os festejos de folia em que tradicionalmente são realizadas essas danças, bem como outras manifestações artísticas ligadas à dança, como o samba, que nomearam de carnaval, ou a valsa, que chamaram de baile. Em um desses debates, alguns alunos chamavam de "gay" bailarinos que dançavam a dança do ventre. Porém, no decorrer das aulas, essa discussão pôde ser aprofundada no intuito de desmistificar as manifestações preconceituosas relacionadas ao gênero que incorrem dessa interpretação, objetivando, desse modo, superar estigmas e formas de sociabilidade discriminatórias.

Nesse sentido, Goellner (2013) aponta a importância dessa desconstrução social, em que determinadas práticas sociais podem ou não ser realizadas por sujeitos de sexo distintos, ou seja, existem signos construídos no decorrer da historicidade humana que segmentam as formas de expressão da cultura humana à identidade de gênero. Contudo, é papel do professor desconstruir esses estereótipos de feminilidade e masculinidade, superando a heteronormatividade e formas preconceituosas de sociabilidade. E essa 
problemática poderia ocorrer, sim, no ensino da curraleira, já que socialmente ela é uma expressão corporal que, na sua construção histórica, exclui as mulheres de sua prática social. Dalla Déa et al (2013) destacam a importância das adaptações para favorecer a inclusão, mesmo que haja algum tipo de dificuldade na adaptação. Defendem o direito de acesso ao saber no processo de formação humana, visto que ainda perdura de forma hegemônica, em nossa sociedade, uma educação machista, que reproduz formas preconceituosas de relação humana.

No decorrer das primeiras aulas, os alunos demonstraram interesse e curiosidade na dança apresentada. E como forma de iniciar a curraleira, foram-lhes mostradas danças populares brasileiras, como o samba, o bumba-meu-boi, o carimbó, o frevo, entre outras, enfatizando suas alteridades. Realizamos ainda cantigas e brincadeiras que exercitaram o ritmo na sua dimensão relacional com a música cantada. Desse modo, aludicidade foi um fator preponderante nesse momento para instigar a curiosidade e também na sequência de atividades para o ensino-aprendizagem da curraleira.

No planejamento inicial, pretendíamos criar, em duas aulas, rimas de curraleira que dialogassem com o cotidiano deles, tendo como ponto de partida a reprodução das cantigas de folia gravadas que utilizamos didaticamente. No entanto, percebemos que estavam com dificuldades na métrica de elaboração das rimas e o tempo pedagógico seria insuficiente para uma avaliação qualitativa. Então, apresentamos os instrumentos utilizados na curraleira aos alunos e realizamos experimentações sensoriais e de musicalização para aproximá-los das técnicas e formas de tocar esses instrumentos. Fizemos a seleção de cantigas já gravadas de curraleira para dar seguimento às aulas e a centralidade da prática pedagógica passou a ser as técnicas e formas de movimentação/giro da curraleira.

Utilizamos, como materiais didáticos para essas atividades, cones para posicionar espacialmente os alunos, marcações no chão para simbolizar o trajeto onde seriam feitas as trocas, comandos sonoros para demarcação do tempo, violão como acompanhamento da música e delimitação rítmica. No decorrer do processo de ensinoaprendizagem, esses materiais foram sendo retirados até os alunos conseguirem se apropriar da totalidade significativa da movimentação estética da curraleira.

Dentre as dificuldades encontradas, destacamos o número excessivo de faltas às aulas dos alunos, sendo necessário retomar ações pedagógicas já realizadas. Outro fator 
dificultador foi a indisciplina, porém, entendíamos que esta constitui parte do processo educativo da educação formal, não sendo inata da criança, como nos aponta Aquino (1996). Sendo assim, buscávamos contemplar, no planejamento, estratégias educativas para superar essa dificuldade, qualificando assim o trabalho pedagógico.

A avaliação formal dos alunos foi realizada a partir dos princípios da escola organizada em ciclos, a saber: dinâmica, contínua, qualitativa, diagnóstica e descritiva. Para além das observações mediadas por roteiros construídos a partir dos objetivos do planejamento, os professores, durante as aulas, realizavam com os alunos processos dialógicos para identificar problemas e/ou dificuldades a serem superadas. Os instrumentos utilizados na avaliação formal da dimensão instrucional foi o diário de bordo (com registros ao final de cada aula), prova escrita/oral e desenhos para analisar a apreensão do conhecimento. A culminância do trabalho foi uma apresentação coreográfica para todos os alunos da escola, realizada no pátio da instituição em dois momentos: o primeiro, com a leitura de um pequeno texto por uma das alunas, que contextualizava a curraleira dentro da folia; e o segundo, com apresentação coletiva valorada e aplaudida por toda a comunidade escolar. Em síntese, estes foram os avanços alcançados nessa intervenção pedagógica, que almejamos poder contribuir para outras experiências educativas que tematizem os saberes da cultura afro-brasileira.

\section{Conclusão}

Como a dança é, segundo Brasileiro (2003), um saber histórico da cultura humana fundamental para a formação estética e a nossa dimensão sensível, sua contribuição para a educação formal é inestimável. Contudo, os currículos escolares, quando não a negligenciam como conteúdo, tendem a selecionar saberes advindos do colonialismo europeu. A partir dessa premissa, faz-se necessária a construção de propostas curriculares e pedagógicas que superem a negação dos saberes da cultura afro-brasileira como formadores da nossa brasilidade e identidade étnica, levando à superação de processos de exclusão social, preconceito e racismo junto aos negros, que, historicamente, foram e são marginalizados em nosso país. Sendo a escola espaço de resistência e instrumento de transformação social, ao se trabalhar seus currículos com os 
saberes da cultura afro-brasileira, há de se contribuir para superar a invisibilidade social desses sujeitos, auxiliando no seu empoderamento e na autoafirmação da sua identidade.

Apesar dos avanços no marco regulatório que obriga a tematização desses saberes na escola, a ausência de material didático-pedagógico que auxilie na mediação desse processo de mudança da cultura escolar é ainda fator preponderante. São, pois, necessárias transformações nos currículos de formação de professores, na formação continuada e de suporte teórico-metodológico das instituições de ensino para repensar seus projetos pedagógicos. E isso implica na reestruturação da organização do trabalho pedagógico, demandando, necessariamente, a mobilização coletiva dos atores da educação formal.

No campo da produção do conhecimento, a educação física, historicamente, negligenciou a sistematização dos saberes da cultura corporal advindos da cultura afrobrasileira e, incluiria aqui, indígena. Nas produções para o campo escolar, a problemática é ainda maior, se considerarmos os conhecimentos identificadores da área, a saber: esporte, jogo/brincadeira, ginástica, luta, dança e arte circense. Com exceção da capoeira, outras manifestações da cultura corporal, ancoradas nesses grupos étnicos aqui citados, são desconsideradas, quando se vislumbra um currículo da educação física escolar.

Desse modo, há uma certa relutância por parte dos alunos em nossa prática pedagógica com a propositura de um saber tão distante de sua realidade social. No entanto, ao final deste trabalho, as ressignificações dos símbolos que envolviam essas práticas sociais ilustraram as necessárias transformações que ainda se fazem urgir em nossa realidade concreta. Por outro lado, houve realizações docentes quando perceberam a possibilidade de ministrar conteúdos diversificados, como a dança afrobrasileira dentro do ambiente escolar, criando assim uma nova cultura escolar. Nessa perspectiva, esperamos que este trabalho abra portas para que novas práticas docentes sejam realizadas ao tematizar a cultura afro-brasileira nas diversas manifestações da cultura corporal. A despeito da folia, faz-se necessária a construção de procedimentos teórico-metodológicos para pedagogizar outras de suas brincadeiras, como o catido, corrido, sussa, batucada etc., ampliando assim as possibilidades dessas práticas sociais na educação formal, com variações de complexificação que se ampliem num currículo espiralado por toda a educação básica. 


\section{Referências}

AQUINO, Júlio Groppa. Confrontos na sala de aula: uma leitura institucional da relação professor-aluno. São Paulo: Summus, 1996.

ALMEIDA, Alfredo Wagner Berno de. Os quilombos e as novas etnias. In: ALMEIDA, Alfredo Wagner Berno de (org). Quilombos: identidade étnica e territorialidade. Rio de Janeiro: Editora FGV, 2002. p.37-65.

ALMEIDA, Roberto Alves de. Relatório antropológico de reconhecimento e delimitação do território da Comunidade Quilombo Família Magalhães. Brasília, DF: Incra, 2007.

ALVAREZ, Gabriel Omar Alvarez; SANTOS, Luiz. Tradições negras, políticas brancas: previdência social e populações afro-brasileiras. 2. ed. Brasília, DF: Ministério da Previdência Social, 2006.

BRANDÃO, Carlos R. Estrutura e processos sociais de reprodução do saber popular: como o povo aprende? v. 2. Campinas: Edições Loyola,1983.

BRASIL. Decreto da Presidência da República - Casa Civil. Subchefia para Assuntos Jurídicos - Lei n. ${ }^{\circ} 11.645$, de 10 de março de 2008 e Lei n. ${ }^{\circ} 10.639$, de 9 de janeiro de 2003. Brasília, DF: Diário Oficial da União.

BRASIL. Fundação Cultural Palmares - Secretaria de Políticas de Promoção da Igualdade Racial (SEPPIR) - Brasil Quilombo, Relatório 2012.

BRASILEIRO, Lívia Tenório. O conteúdo "dança" em aulas de Educação Física: Temos o que ensinar? Pensar a Prática, Goiânia, v. 6, p. 45-58, Jul./Jun. 2002-2003.

COLETIVO DE AUTORES. Metodologia do Ensino de Educação Física. São Paulo: Editora Cortez, 2012.

DALLA DÉA, Vanessa Helena Santana et al. Inclusão de Pessoas com Deficiência nos Projetos de Extensão de Práticas Corporais da Universidade Federal de Goiás. Pensar a Prática, Goiânia, v. 16, n. 4, p. 956-1270, out./dez. 2013.

DEMO. P. Conhecimento Moderno: sobre ética de intervenção do conhecimento. Petrópolis, RJ: Vozes, 1997.

GOELLNER, Silvana V. A contribuição dos estudos de gênero e feministas para o campo acadêmico profissional da educação física. In: GOELLNER, Silvana V (org). Educação física e gênero: desafios educacionais. Ijuí: Editora Unijuí, 2013. p. 23-43.

KARASCH, Mary. Os quilombos de ouro na capitania de Goiás. In: REIS, João José; GOMES, Flávio dos Santos. Liberdade por um fio: história dos quilombos no Brasil. 4. ed. São Paulo: Companhia das Letras, 1996. p. 103-138. 
LIMA, Luana Nunes Martins de. O território simbólico da festa kalunga de Nossa Senhora Aparecida: organização social, rituais e sentidos. In: SIMPÓSIO NACIONAL DE HISTÓRIA, Natal: Anais do evento. 2013.

O’DWYER, Eliane Cantarino (Org.). Quilombos: identidade étnica e territorialidade. Rio de Janeiro: Editora FGV/ABA, 2002.

PEDROZA, Reigler Siqueira. A performance da folia de São Sebastião: aspectos simbólicos de um ritual na comunidade quilombola Magalhães - GO. 2013. 118f. Dissertação (Mestrado em Antropologia Social) - Faculdade de Ciências Sociais, Universidade Federal de Goiás, Goiânia, 2013.

PESSOA, Jadir de Morais; FÉLIX, Madeleine. As viagens dos Reis Magos. Goiânia: Editora da UCG, 2007.

RATTS, Alecsandro Alex J. P; FURTADO, George da Cunha. Observações sobre a situação dos quilombos em Goiás. In: Caderno de Debates $\mathrm{n}^{\circ} .02$ - Territórios, quilombolas e conflitos. Manaus: UEA Edições, 2010. p. 235-241.

SAVIANI, D. Escola e Democracia: teorias da educação, curvatura da vara, onze teses sobre educação e política. 31. ed. Campinas: Autores Associados, 1997.

SILVA, Martiniano José da. Quilombos do Brasil Central: séculos XVIII e XIX (17191888). Introdução ao estudo da escravidão. Goiânia: UFG, 1998.

STRAZZACAPPA, Márcia. Dança na educação: discutindo questões básicas e polêmicas. Pensar a Prática, Goiânia, v. 6, p. 73-85, Jul./Jun. 2002-2003. 